\title{
PENGARUH TINGKAT PENGHINDARAN PAJAK TERHADAP NILAI PERUSAHAAN DENGAN BIAYA AGENSI SEBAGAI VARIABLE MEDIASI
}

\author{
Centisya Ariska \\ Program Studi Magister Manajemen Universitas Tarumanagara \\ centisya@gmail.com
}

Masuk : 04-12-2020, revisi : 23-12-2020, diterima untuk diterbitkan : 23-12-2020

\begin{abstract}
This study aims to analyze and determine the effect of tax avoidance rate on the value of the firm and agency cost as a mediation in manufacturing industry's companies that listed in BEI in 2015-2019. With purposive sampling, the researcher found 45 companies matched with the research. The researcher used Path Analysis and regression for hypothesis test and found the result that tax avoidance is significant to firm value and agency cost, agency cost is significant to firm value, and mediation in partial relationship between tax rate avoidance and firm value.
\end{abstract}

Keywords: Tax Avoidance, Agency Cost, Firm Value

\begin{abstract}
Abstrak: Penelitian ini bertujuan untuk mengetahui pengaruh dari tingkat penghindaran pajak terhadap nilai perusahaan dan biaya agensi sebagai mediasinya dalam perusahaan industri manufaktur yang terdaftar di BEI tahun 2015-2019. Dengan menggunakan purposive sampling, didapatkan 45 perusahaan yang tepat untuk penelitian ini. Peneliti menggunakan metode analisis jalur dan regresi untuk pengujian hipotesis. Hasilnya adalah tingkat penghindaran pajak signifikan terhadap nilai perusahaan dan biaya agensi. Biaya agensi juga signifikan terhadap nilai perusahaan dan memediasi secara parsial hubungan antara tingkat penghindaran pajak dan nilai perusahaan.
\end{abstract}

Kata Kunci: Penghindaran Pajak, Biaya Agensi, Nilai Perusahaan

\section{PENDAHULUAN}

Tujuan perusahaan adalah meningkatkan nilainya yaitu kekayaan pemegang saham yang terpapar dalam harga saham perusahaan. Teori Agensi menyebutkan perusahaan terdiri atas pemilik dan agen. Tugas agen adalah meningkatkan nilai sang pemilik membayar agen tersebut atas jasa yang telah mereka lakukan. Pemilik perusahaan tentunya menginginkan agar manajemen terkontrol dengan baik dan tidak melenceng dengan tujuan sang pemilik sehingga mereka melakukan pengawasan agar agen tidak bertindak demi kepentingannya sendiri.

Salah satu strategi yang banyak mendapat sorotan adalah penghindaran pajak, di satu sisi ini mampu menaikkan nilai namun ada resiko yang harus ditanggung bila melanggar aturan. Cai dan Liu (2009) dalam Adityamurti dan Ghozali (2017) berpendapat strategi yang bisa digunakan dalam merencanakan pengelolaan pajak adalah penghindaran pajak. Penghindaran pajak tersebut berarti usaha dari badan atau perorangan untuk menekan rendah tingkat pajak yang dibayarkan dengan melaksananakan praktik tersebut secara legal dan sesuai peraturan perpajakan yang berlaku. Tapi perlu juga diketahui penghindaran pajak tidak tanpa resiko, perusahaan harus memikirkan biaya yang mungkin bisa terjadi seperti dampaknya pada reputasi, potensi hukum, dsb.

Penelitian tentang pajak dan nilai perusahaan telah dilakukan oleh Assidi et al. (2016) dengan data di Tunisia menunjukkan hasil yaitu penghindaran pajak mempengaruhi nilai perusahaan secara negatif yang menunjukkan bahawa dengan menghindari pajak akan menurunkan nilai perusahaan, hal sama juga ditemukan Santana dan Rezende (2016) dengan data di brazil. Kurniawan dan Syafruddin (2017) serta Hanif dan Ardiyanto (2019) dengan data di Indonesia menunjukkan hasil penghindaran pajak mempengaruhi nilai perusahaan secara 
positif yang mana artinya bahwa dengan menghindari pajak akan meningkatkan nilai perusahaan nilai perusahaan tersebut. Lalu penelitian lainnya Razali et al. (2018) dengan data di Malaysia menunjukkan bahwa dengan 2 proxy berbeda untuk menghitung penghindaran pajak menghasilkan hasil yang berbeda.

\section{Tujuan Penelitian}

Penelitian ini ditujukan untuk melihat pengaruh variable independen terhadap dependen, sebagai berikut:

1. Apakah tingkat penghindaran pajak mempengaruhi nilai perusahaan?

2. Apakah tingkat penghindran pajak mempengaruhi biaya agensi?

3. Apakah biaya agensi mempengaruhi nilai perusahaan?

4. Apakah biaya agensi memediasi hubungan antara tingkat penghindaran pajak dan nilai perusaaan?

\section{TINJAUAN PUSTAKA}

Agency theory mengatur hubungan antara pemilik perusahaan dan agen. Jensen dan Meckling (1976) menjelaskan bahwa teori ini menjelaskan kontrak yang terjadi antar keduanya. Principal memberi modal dan mendapat return dan agen yang menjalakan pekerjaan akan mendapat imbalan berupa gaji, komisi, dan lain-lain. Dalam pelaksanaannya kedua belah pihak bisa tidak selaras. Agen bisa bertindak atas kepentingannya sendiri, sehingga perlu pengawasan dari pemilik perusahaan yang menimbulkan biaya yaitu agency cost.

Signaling theory menurut Nurzanah et al. (2016) adalah ada asimetri informasi antara manajemen dan pihak yang berkepentingan. Manajemen harus menyediakan informasi kepada pihak terkait dengan menerbitkan laporan keuangan tahunan. Perusahaan secara kualitatif memiliki informasi yang lebih banyak jika dibandingkan dengan pihak luar dan manjemen harus menggunakan ukuran-ukuran dan fasilitas tertentu untuk menjelaskan kualitas perusahaannya.

Nilai perusahaan merefleksikan nilai atas bisnis tersebut. Nilai itu merupakan jumlah yang harus dibayarkan bagi mereka yang ingin membeli/mengambil alih bisnis tersebut (eFinancialManagement, 2018). Penghindaran pajak menurut Yee et al. (2018) merupakan aktifitas penghematan pajak yang mana menambah nilai perusahaan. Secara umum penghindaran pajak adalah skema yang bertujuan meminimalkan beban pajak dengan memanfaatkan celah (loophole) ketentuan perpajakan suatu negara. Biaya agensi merupakan biaya tambahan yang sengaja dikeluarkan untuk mensejajarkan kepentingan principal dan agen. Adityamurti dan Gozali (2017) berpendapat bahwa biaya agensi muncul ketika prinsipal menginginkan terkontrolnya tindakan agen sehingga tidak merugikan prinsipal.

\section{Gambar 1}

\section{Kerangka Pemikiran}
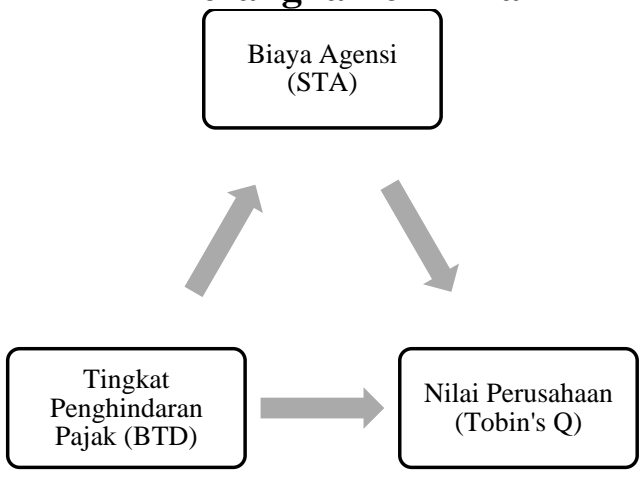

Hipotesis atas kerangka pemikiran tersebut:

H1: Penghindaran pajak berpengaruh secara signifikan positif pada biaya agensi.

H2: Penghindaran pajak berpengaruh signifikan negative terhadap nilai perusahaan.

H3: Biaya agensi berpengaruh secara signifikan positif terhadap nilai perusahaan. 


\section{METODOLOGI PENELITIAN}

Populasi dalam penelitian ini adalah perusahaan yang terdaftar dan masih aktif di Bursa Efek Indonesia (BEI) tahun 2015-2019. Data-data diperoleh dari laporan tahunan perusahaan dari website www.idx.co.id. Metode pemilihan sampel adalah purposive sampling. Kriteria yang digunakan sebagai berikut: 1) Perusahaan yang terdaftar di BEI dari tahun 2015-2019;2) Memiliki data keuangan yang lengkap selama periode penelitan; 3) Perusahaan dalam sektor manufaktur; 4) Perusahaan yang tidak mengalamai rugi akuntansi dan rugi fiskal di 2015-2019.

Terdapat 138 perusahaan yang listing dan aktif di BEI. Peneliti menemukan 45 perusahaan yang bisa dijadikan sampling. Peneliti mengunakan metode analisa jalur dan membuktikan hipotesis dengan regresi linear berganda.

Variabel dependen adalah nilai perusahaan diukur dengan Tobin's Q, yang menggambarkan nilai perusahaan di pasar dengan aset perusahaan saat ini, bila semakin tinggi nilannya maka perusahaan tersebut sangat baik nilai perusahaannya. Tobin's Q dihitung dengan mengkalikan nilai saham terhadap saham beredar ditambah nilai buku utang lalu dibagi dengan nilai buku perusahaan (Chung \& Pruitt, 1994). Variabel independen tingkat penghindaran pajak dihitung dengan BTD. Perhitungan selisih laba akuntansi dan fiskal dibagi total aset (Razali et al., 2018). Variabel mediasi yang digunakan yaitu biaya agensi, dihitung dengan penjualan dibagi total aset, untuk melihat seberapa baik perusahaan menggunakan asetnya.

Dalam penelitian ini menggunakan uji statistik deskriptif untuk menguji penyebaran data sampel, lalu dilanjutkan dengan uji asumsi klasik normalitas, multikolinearitas, heterokedasitas dan autokorelasi. Kemudian dilakukan uji jalur dengan 2 model uji $t$ dan terkahir uji koefisien korelasi.

Model $1: \mathrm{AC}_{1 \mathrm{i}, \mathrm{t}}=\mathrm{a}+\mathrm{b}_{1.1} \mathrm{BTD}+\varepsilon$

Model 2 : Tobins' $q_{1 i, t}=a+b_{1 .}{ }_{2} B T D+b_{1 .} A C+\varepsilon$

\section{HASIL DAN KESIMPULAN}

Analisa deskriptif Nilai perusahaan dalam penelitian ini didapat, rata-rata nilai perusahaan yaitu 4.064, dengan nilai minimum 0.06 dan maksimum 38.3. Tingkat penghindaran pajak diperoleh rata-rata sebesar 0.023, nilai maksimum sebesar 0.31 dan nilai minimum (-0.14) yang artinya perhitungan fiskal lebih tinggi dari perhitungan akuntansi. Biaya agensi nilai rata-ratanya 1.1062 , nilai maksimum 3.06 dan nilai minimum 0.24.

Hasil dari uji asumsi klasik yaitu:

1. Uji normalitas dan P-Plot

\section{Gambar 2}

Hasil Uji Normalitas Model 1

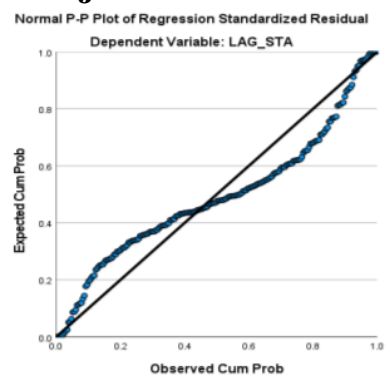

\section{Gambar 3}

Hasil Uji Normalitas Model 2

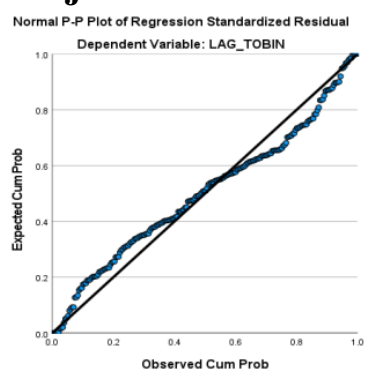

Kedua gambar menunjukkan titik/plot mengikuti garis diagonal yang artinya data terdistribusi dengan normal.

2. Uji Multikolinearitas kedua model menunjukkan tolerance $>0.1$ dan VIF $<10$ ini menunjukkan tidak terjadi multikolinearitas.

3. Uji Heterokedasitisas dengan Uji Jack menunjukkan hasil sig > 0.05 maka tidak terdapat heterokedasitisas di model penelitian. 
4. Uji Autokorelasi menunjukkan model $1 \mathrm{DW}=1.987$ yang artinya lebih besar dari $\mathrm{dL}$ sebesar 1.77525 dan lebih kecil dari (4-1.79270) yaitu 2.2073. dan model $2 \mathrm{DW}=1.953$ yang artinya lebih besar dari dL sebesar 1.76647 dan lebih kecil dari (4-1.81054) yaitu 2.18946. tidak terjadi masalah autokorelasi.

Berdasarkan hasil pengujian yang dilakukan, peneliti memberikan pokok-pokok temuan penelitian secara keseluruhan. Hasil analisis berganda adalah sebagai berikut:

\section{Tabel 1}

Uji Statistika Model 1

\begin{tabular}{|c|c|c|c|c|c|c|}
\hline \multirow{2}{*}{ Model } & \multicolumn{2}{|c|}{ Unstandardized Coefficients } & Standardized Coefficients & \multirow{2}{*}{$\mathrm{t}$} & \multirow{2}{*}{ Sig. } \\
\cline { 3 - 7 } & B & Std. Error & Beta & 11.495 & .000 \\
\hline \multirow{2}{*}{1} & (Constant) & .239 & .021 & & 2.031 & .043 \\
\cline { 2 - 7 } & LAG_BTD & .942 & .464 & .135 & & \\
\hline
\end{tabular}

Sumber: IMB SPSS 2020)

\section{Tabel 2}

Uji Statistika Model 2

\begin{tabular}{|c|c|c|c|c|c|c|}
\hline & \multirow{2}{*}{ Model } & \multicolumn{2}{|c|}{ Unstandardized Coefficients } & \multirow{2}{*}{$\frac{\text { Standardized Coefficients }}{\text { Beta }}$} & \multirow{2}{*}{$\mathrm{t}$} & \multirow{2}{*}{ Sig. } \\
\hline & & $\mathrm{B}$ & Std. Error & & & \\
\hline \multirow{3}{*}{1} & (Constant) & .019 & .025 & & .744 & .457 \\
\hline & LAG_BTD & 1.201 & .454 & .174 & 2.646 & .009 \\
\hline & LAG_STA & .167 & .065 & .168 & 2.568 & .011 \\
\hline
\end{tabular}

Sumber: IMB SPSS 2020)

Model 1 menunjukkan BTD perpengaruh sihnifikan positif terhadap biaya agensi. Model 2 menunjukkan BTD (tingkat penghindaran pajak) dan STA (biaya agensi) berpengaruh signifikan positif terhdap Tobin's Q (nilai perusahaan) dan STA (biaya agensi).

\section{Tabel 1}

Hasil Uji Koefisien Determinasi Model 1

\begin{tabular}{|c|c|}
\hline$R$-squared & 0.018 \\
\hline Adjusted R-squared & 0.014 \\
\hline
\end{tabular}

\section{Tabel 2}

Hasil Uji Koefisien Determinasi Model 2

\begin{tabular}{|c|c|}
\hline$R$-squared & 0.066 \\
\hline Adjusted $R$-squared & 0.058 \\
\hline
\end{tabular}

Dari hasil Tabel 1, nilai $R$-squared adalah sebesar 0.018 atau $1.8 \%$, artinya penghindaran pajak mampu menjelaskan biaya agensi pada perusahaan industri manufaktur sebesar $1.8 \%$, sedangkan nilai $R$-squared adalah sebesar 0.066 atau $6.6 \%$, artinya nilai perusahaan pada perusahaan industri manufaktur sebesar 6.6\%. Dapat dijelaskan dengan variable penghindaran pajak dan biaya agensi.

Teori agensi menjelaskan perbedaan kepentingan di sisi agen mereka melakukan penghindaran pajak demi mendapatkan laba lebih tinggi dan menarik investor. Namun prinsipal menginginkan sistem manajemen yang benar sehingga mereka mewaspadai strategi tersebut. Rasio tingkat penghindaran pajak yang tinggi mengakibatkan biaya agensi yang meningkat. Ini sesuai dengan penelitian Adityamurti dan Ghozali (2017) serta Anggoro dan Septiani (2015).

Strategi manajemen salah satunya adalah mengurangi beban pajaknya sehingga laba perusahaan akan naik dan meningkatkan nilai perusahaannya. Hasil penelitian ini menunjukkan strategi tersebut dapat berhasil. Tingginya tingkat penghindaran pajak menaikkan nilai perusahaan. Hasil ini sesuai dengan penelitian yang dilakukan Kurniawan dan Syafruddin (2017) serta Anggoro dan Septiani (2015). Biaya agensi akan membuat manajemen perusahaan semakin membaik karena pengawasan tersebut meminimalisir kecurangan dan pemilik. Hal ini sesuai dengan penelitian Adityamurti dan Ghozali (2017). Tingkat penghindaran pajak signifikan terhadap nilai perusahaan dan berpengaruh signifikan terhadap biaya agensi. Biaya agensi berpengaruh terhadap nilai perusahaan. Berdasarkan hasil ini maka biaya agensi adalah mediasi parsial. 
Saran dari peneliti untuk penelitian selanjutnya menambahkan industri lainnya dan mendapatkan hasil setinggi apa tingkat penghindaran pajak yang optimal untuk bisa meningkatkan nilai perusahaan. Penelitian selanjutnya bisa menggunakan proxy lain seperti ETR dan CETR yang merupakan rasio pengukuran penghindaran pajak. Jika perusahaan ingin melakukan penghindaran pajak, berdasarkan hasil dari penelitian ini tingkat BTD hingga 3\% masih mampu untuk menaikkan nilai perusahaan. Perusahaan diharapkan untuk mencermati aturan perpajakan agar tidak dianggap melanggar aturan. Untuk investor penghindaran pajak bisa menaikkan nilai perusahaan disertai dengan naiknya biaya agensi. Dapat dikatakan tindakan dan pengawasan berjalan beriringan dan terjadi sinergi dan resiko atas pelanggaran lebih terjamin. Namun pastikan perusahaan tersebut memiliki reputasi baik jika ingin berinvestasi di sana.

\section{DAFTAR PUSTAKA}

Adityamurti, E., \& Ghozali, I. (2017). Pengaruh penghindaran pajak dan biaya agensi terhadap nilai perusahaan. Diponegoro Journal Of Accounting, 6(3), 124-135. https://ejournal3.undip.ac.id/index.php/accounting/article/view/18228

Anggoro, S. T., \& Septiani, A. (2015). Analisis pengaruh perilaku penghindaran pajak terhadap nilai perusahaan dengan transparansi sebagai variabel moderating. Diponegoro Journal of Accounting, 4(4), 437-446. https://ejournal3.undip.ac.id/index.php/accounting/article/view/9598

Assidi, S., Aliani, K., \& Omri, M. A. (2016). Tax optimization and the firm's value: Evidence from the Tunisian context. Borsa Istanbul Review, 16(3), 177-184. https://doi.org/10.1016/j.bir.2016.04.002

Chung, K. H., \& Pruitt, S. W. (1994). A simple approximation of Tobin's Q. Financial Management, 23(3), 70-74. https://doi.org/10.2307/3665623

eFinancialManagement. (2018). Value of a firm. Efinancialmanagement.Com. https://efinancemanagement.com/investment-decisions/value-of-a-firm

Hanif, I. N., \& Ardiyanto, M. D. (2019). Analisis pengaruh praktik penghindaran pajak terhadap nilai perusahaan: Transparansi informasi sebagai variabel pemoderasi. Diponegoro Journal of Accounting, 8(3), 1-12. https://ejournal3.undip.ac.id/index.php/accounting/article/view/25714/22885

Jensen, M. C., \& Meckling, W. H. (1976). Theory of the firm: Managerial behavior, agency costs and ownership structure. Journal of Financial Economics, 3(4), 305-360. https://doi.org/10.1016/0304-405X(76)90026-X

Kurniawan, A. F., \& Syafruddin, M. (2017). Pengaruh penghindaran pajak terhadap nilai perusahaan dengan variabel moderasi transparansi. Diponegoro Journal of Accounting, 6(4), 94-103. https://ejournal3.undip.ac.id/index.php/accounting/article/view/18199

Nurzanah, Y., Kopong, \& Riska. (2016). Pengaruh growth opportunity dan ukuran perusahaan terhadap profitabilitas dengan nilai perusahaan sebagai variabel moderating pada perusahaan manufaktur yang terdaftar di Bursa Efek Indonesia. Jurnal Akuntansi Manajerial, 1(1), 116-133.

Razali, M. W. M., Ghazali, S. S., Lunyai, J., \& Hwang, J. Y. T. (2018). Tax planning and firm value: Evidence from Malaysia. International Journal of Academic Research in Business and Social Sciences, 8(11), 210-222. https://doi.org/10.6007/ijarbss/v8i11/4896

Santana, S. L. L., \& Rezende, A. J. (2016). Corporate tax avoidance and firm value: evidence from Brazil. Revista Contemporânea de Contabilidade, 13(30), 114-133. https://doi.org/10.5007/2175-8069.2016v13n30p114

Yee, C. S., Sapiei, N. S., \& Abdullah, M. (2018). Tax avoidance, corporate governance and firm value in the digital era. Journal of Accounting and Investment, 19(2), 160-175. https://doi.org/10.18196/jai.190299 